\section{REPROCESSING OF STYRENE ACRYLONITRILE AND THE INFLUENCE OF THE PARTICLE SIZE ON TENSILE PROPERTIES}

\section{VOJTECH SENKERIK, MARTIN OVSIK, MARTIN REZNICEK, VACLAV JANOSTIK}

Tomas Bata University in Zlin, nam. T. G. Masaryka 5555, 76001 Zlin, Czech Republic

DOI : 10.17973/MMSJ.2019_03_201862

e-mail: vsenkerik@utb.cz

The purpose of this work is to determine the influence of the reprocessed polymer on tensile properties. Tested samples were obtained using the injection molding technology from the industrial unpolluted waste, which is the same material like the virgin styrene acrylonitrile (SAN). The waste was milled for further reprocessing and a mixture of different particles was obtained. This mixture was sifted to fraction differ by particle sizes. These mixtures were characterized by tensile testing at the ambient temperature. It was found that mixtures with small particles influenced the non-sifted milled mixture even though these particles contain only a small amount.

KEYWORDS

Reprocessing, sifting, particle size, styrene acrylonitrile, tensile properties.

\section{INTRODUCTION}

Products made by injection molding have either character of final product or are semi products for consequent assembly into next complex product. Products made by injection molding are distinguished by very precise dimensions and shape, and also by great reproducibility of mechanic and physical properties. Injection molding technology is most wide-spread technology in plastic manufacturing; it is discontinuous and cyclic process. Almost all kinds of thermoplastics can be injected. Some thermosetting polymer and rubbers can be injected as well. [Brandrup 1996], [Manas 2018]

Within a closed loop cycle, it is easy to recycle materials and this is the reason that primary recycling is so commonplace. The key is having the knowledge of, and confidence in, the materials that are being used.

Defective injects, waste and runner system originating during injection molding can be processed several times. This way of processing is frequently used because of high portion of the waste, especially while manufacturing small injects. For this reason is unpolluted waste cut and crushed. Material modified by this process is once again granulated and mixed with pure granulate and consequently utilized. Using this mixed material has usually no significant influence on physical-mechanical properties or surface appearance. Level of properties degradation depends on levels of crushed material in original material. Transparent and highly stressed materials cannot be mixed, because of high demands. [Scelsi 2011], [Navratil 2014] Mechanical recycling consists in recovering waste material by means of thermos-physical processes. This recycling of plastics presents several technical, economical and marketing challenges.
Mechanical recycling is the most common method of recycling. Here plastics are physically ground back to a suitable size (regrind) and reprocessed. The end use can be the original one or something different. [Ragan 2012], [Skrobak 2014]

In general, variability of product composition and color leads to difficulties in obtaining a product with a consistent set of properties, and sourcing an adequate supply of a reasonably clean feedstock is often the crucial step in determining the economics of the recycling process and the quality of the recycled products. Processability and physical properties of recycled products can be considerably deteriorated with respect to virgin polymers. This is mainly due to the following effect polymer degradation. [Ovsik 2016]

Degradation of polymers are subject to negative changes in their macroscopic properties due to subtle modification of molecular structure that can result from the following environmental factors: thermal-oxidative processes that can occur during molding or even at room temperature, attack by pollutant gasses, chemical interaction with liquid contents, and others. Degradative processes are often accelerated by the presence of certain impurities. [Goodship 2007], [La Mantia 1993]

\section{EXPERIMENT}

The aim of the work is to find out the influence of the reused material which differ by particle sizes on the mechanical properties. Studied material is styrene acrylonitrile. The goal is to recycle SAN waste, reprocessed it and put it to mechanical tests.

\subsection{Production of specimens}

The specimens were prepared by the injection molding technology on the injection molding machine Arburg Allrounder $470 \mathrm{H}$. Each of the specimens were left to condition for $24 \mathrm{~h}$ before testing. Process parameters were used by polymer producer recommendation.

\subsection{Milling}

After production of virgin styrene acrylonitrile, non-used parts (such as runner system) were used for other reprocessing. But size of waste must be reduced. For this size reduction milling technology was used. Milling was carried out on the Maskain AB GK 2218 knife mill. The mill output was a mixture containing particles of various sizes including dust particles. This dust particles caused small problem with manipulation because of static electricity. Very light dust particles glued to every surface. [Navratil 2015] , [Senkerik 2014]

\subsection{Sifting}

After the creation of the milled mixture, this mixture was divided to individual group by particle size. This was done on the laboratory AS 200 Basic sifting machine. The sifter consists of four sieves that divide the mixture by size, sieves with holes $4 \mathrm{~mm}, 3 \mathrm{~mm}, 2 \mathrm{~mm}, 1 \mathrm{~mm}$ and bottom bowl which collect fine dust particles. Sieve with $4 \mathrm{~mm}$ holes collect particles larger than $4 \mathrm{~mm}$, but size do not exceed $5 \mathrm{~mm}$.

The Fig. 1 shows that the largest proportions have particles larger than $2 \mathrm{~mm}$ and smaller than $3 \mathrm{~mm}$. Weight ratio is $45 \%$ for this mixture. The smallest particles and the largest particles have $4 \%$ ratio. Mixture with particles size $3-2 \mathrm{~mm}$ representing a further $36 \%$ by weight ratio. 


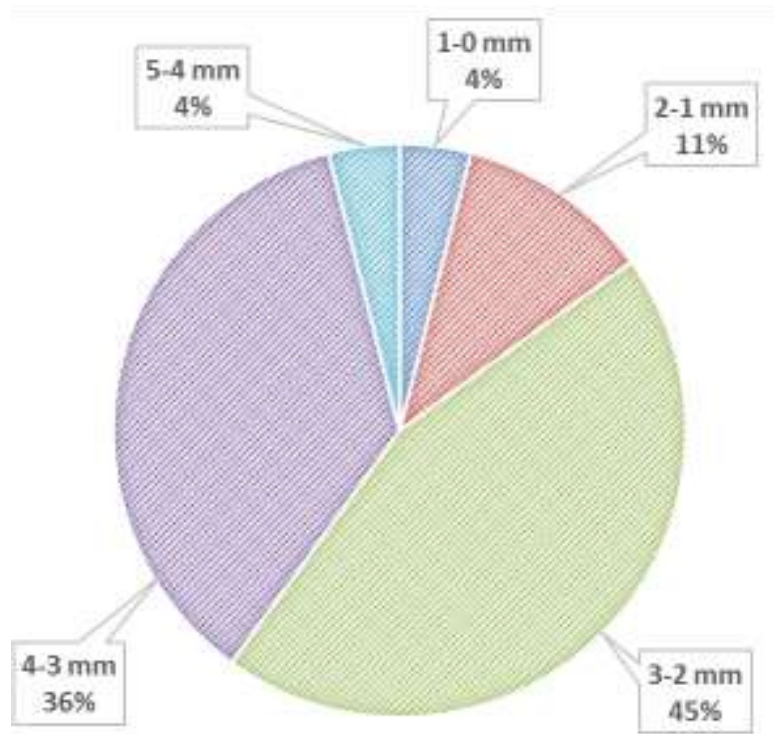

Figure 1: Weight ratio of particle size of the total milled mixture

\subsection{Production of specimens}

The specimens were prepared by the injection molding technology on the injection molding machine Arburg Allrounder $470 \mathrm{H}$. Each of the specimens were left to condition for $24 \mathrm{~h}$ before testing. Process parameters were used by polymer producer recommendation.

\subsection{Composition of tested mixtures}

After obtaining of milled mixture, the new products specimens were made by injecting molding technology. Mixtures differ in particle size of sifted particles. Injection took place at the same injection parameters for all mixtures. After the injection, the runner system was removed from the products, resulting in finished specimens that were subjected to mechanical tests. [Senkerik 2016], [Stanek 2011]

For the injection, the following mixtures were used:

- Virgin SAN = original granule of thermoplastic material styrene acrylonitrile that not yet been processed, reference material which is compared with the recycled mixtures

- SAN 5- $4 \mathrm{~mm}$ = sifted recycled material larger than $4 \mathrm{~mm}$, top sieve separated this particles larger than $4 \mathrm{~mm}$ but size did not exceed $5 \mathrm{~mm}$

- SAN $4-3 \mathrm{~mm}=$ sifted recycled material with a particle size from $4 \mathrm{~mm}$ to $3 \mathrm{~mm}$

- SAN $3-2 \mathrm{~mm}=$ sifted recycled material with a particle size from $3 \mathrm{~mm}$ to $2 \mathrm{~mm}$

- SAN 2 - $1 \mathrm{~mm}=$ sifted recycled material with a particle size from $2 \mathrm{~mm}$ to $1 \mathrm{~mm}$

- SAN 1 - $0 \mathrm{~mm}=$ sifted recycled material with a particle size from $1 \mathrm{~mm}$ to $0 \mathrm{~mm}$, mixture with very small dust particle which remained in the lower bowl

- $\quad$ Milled SAN = Fig. 3 shows non-sifted milled recycled mixture that include all particles sizes, from dust to particles to large particles up to $5 \mathrm{~mm}$, taken directly from the knife mill

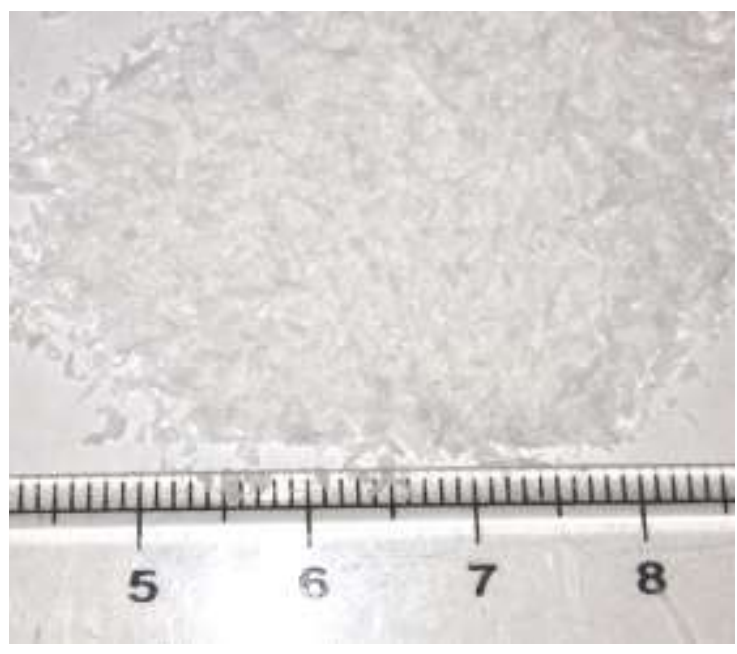

Figure 2: PP 1-0 mm mixture

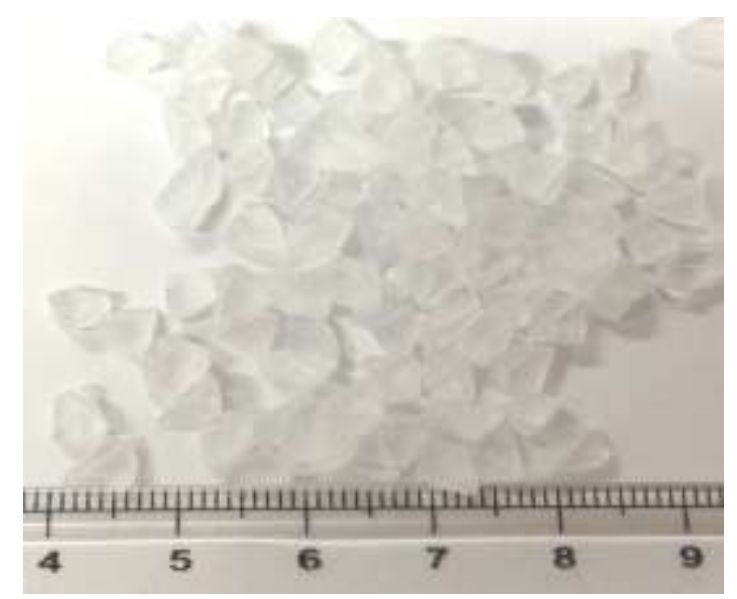

Figure 3: PP 5-4 mm mixture

Table 1: Tested mixtures

\begin{tabular}{|c|c|}
\hline Composition of tested mixtures & Particle size [mm] \\
\hline Virgin SAN & granule \\
\hline SAN $5-4 \mathrm{~mm}$ & $5>x>4$ \\
\hline SAN $4-3 \mathrm{~mm}$ & $4>x>3$ \\
\hline SAN $3-2 \mathrm{~mm}$ & $3>x>2$ \\
\hline SAN $2-1 \mathrm{~mm}$ & $2>x>1$ \\
\hline SAN $1-0 \mathrm{~mm}$ & $1>x>0$ \\
\hline Milled SAN & All sizes \\
\hline
\end{tabular}

\section{TESTED MATERIAL}

Tested polymer was styrene acrylonitrile Starex $\mathrm{HF} 5661 \mathrm{H}$. Styrene acrylonitrile resin is a copolymer plastic consisting of styrene and acrylonitrile. The chains of the polymer show alternating repeat units. Larger acrylonitrile content improves mechanical properties and chemical resistance, but also adds a yellow tint to the normally transparent plastic. 
SAN is optically transparent and brittle in mechanical behavior. The copolymer has a glass transition temperature greater than $100^{\circ} \mathrm{C}$ owing to the acrylonitrile units in the chain, thus making the material resistant to boiling water. It is structurally related to ABS plastic, where polybutadiene is copolymerized with SAN to give a much tougher material.

\section{TESTING}

Mechanical testing consisted of static tensile test. Tensile properties were measured in accordance with the procedure in EN ISO 527 standard on a universal tensile testing machine 1456 from Zwick / Roel. Measurements were performed at ambient temperatures. Each of the specimens according to the size of particles were subjected always to ten measurements.

\section{RESULTS}

All graphs are normalized that the virgin material is $100 \%$. Other values are derived from the nominal values.

\subsection{Elastic tensile modulus}

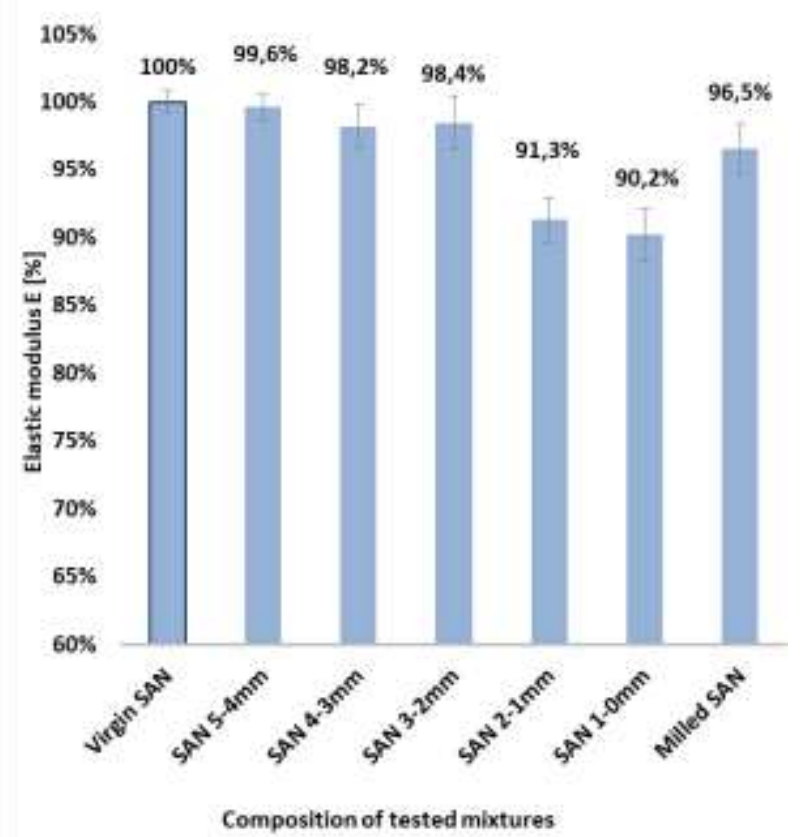

Figure 4: Elastic modulus

The values of the elastic modulus characterizing the stiffness, the highest values were reached for virgin styrene acrylonitrile (3430 MPa) and samples with a particle size of $5-4 \mathrm{~mm}$. The lowest values were found for dust particles and samples with a particle size of $1-2 \mathrm{~mm}$. The drop in modulus values is almost $10 \%$ lower than the virgin material. The decrease in the values can be explained by the wear of the polymer chains due to the greater straining in the crushing process. The milled non-sifted SAN shows a nearly $4 \%$ decrease in the modulus after the first recycling. Mixtures with larger particles 2 to $4 \mathrm{~mm}$ have almost no decrease in the modulus of elasticity.

\subsection{Ultimate tensile strength}

The measured values in the tensile test come out that the samples with particles of $5-4 \mathrm{~mm}$ showed the ultimate tensile strength. However, this is a negligible difference compared to the virgin styrene (70 $\mathrm{MPa})$ acrylonitrile and is given only within the standard deviation. The strength decrease more strongly for all other recycled mixtures. For sifted particles with size from 3 to $0 \mathrm{~mm}$ strength values a decrease more than $5 \%$. The milled non-sifted SAN shows a relatively small decrease in the strength value, just over $2 \%$ of the virgin material.

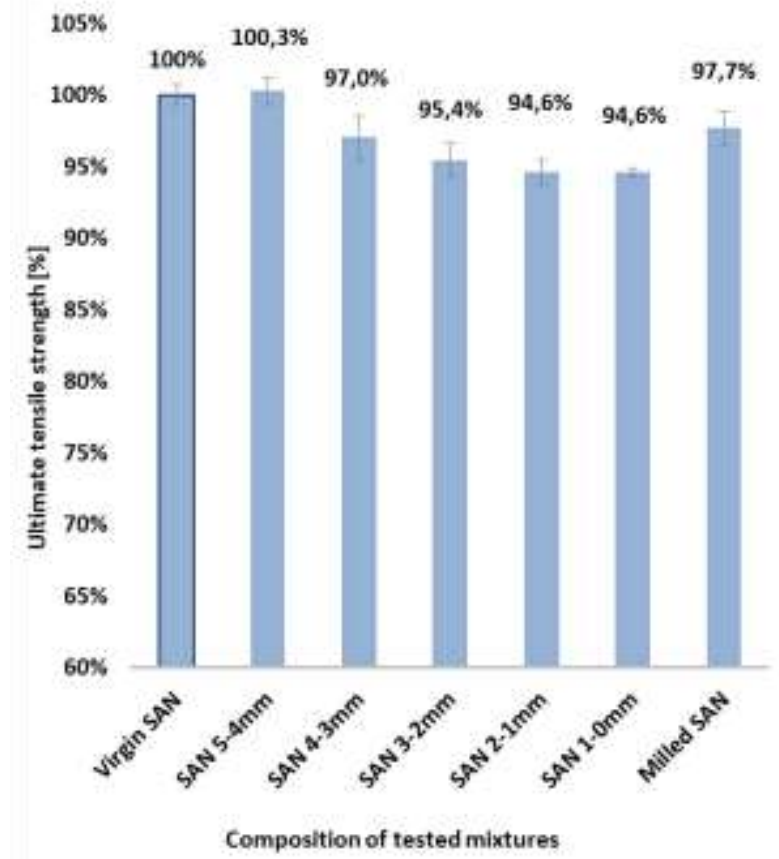

Figure 5: Ultimate tensile strength

\subsection{Strainss}

If it is possible to refer to the elongation resistance of the test samples, it is to be seen from Fig. 6 that the course of strain values is similar in character to the previous case of ultimate tensile strength. The longest elongation occurred in the virgin styrene $(4.3 \%)$ acrylonitrile and the mixture with large particles 5-4 mm.

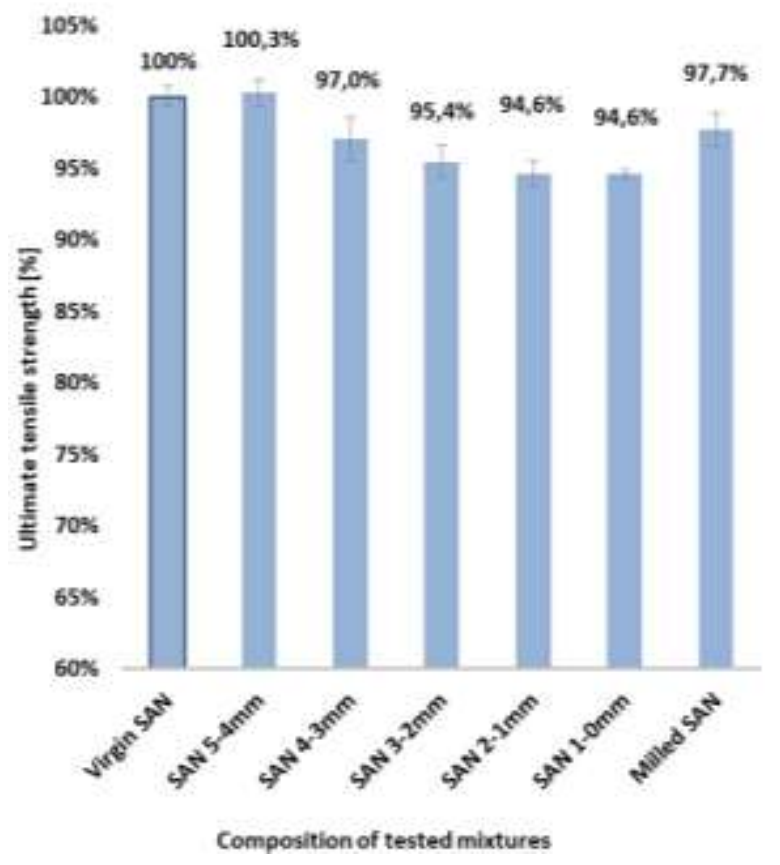

Figure 6: Strain 
Sifted mixtures with a particle size of 3 to $0 \mathrm{~mm}$ again show similar values about $5 \%$ lower than the virgin material. The milled non-sifted SAN and SAN $4-3 \mathrm{~mm}$ have similar elongation values. These elongation changes can be correlated to the tensile strength, when the strength reduces and hence reduces the elongation of the test specimens.

\section{CONCLUSIONS}

The aim of this work was to measure the styrene acrylonitrile thermoplastic polymer, which was reprocessed. Unpolluted waste from the injection molding technology was crushed and crushed mixture was obtained with various large particles. This mixture is the same material as the virgin original material. Subsequently, mixtures were prepared which differed in particle sizes after sifting, from small particles to large particles. The test mixtures were subjected to tension testing at ambient temperature. The virgin SAN was taken as reference material.

The measured results show that the elastic tensile modulus decrease by about $10 \%$, especially for dust particles due to reprocessing. Mixtures with a particle size of 5 to $2 \mathrm{~mm}$ exhibit minimal changes in modulus values.

Another evaluated property is the ultimate tensile strength. There can be seen that the mixture with particle size $5-4 \mathrm{~mm}$ has a slightly higher value of strength than the virgin material, so that there is no degradation of the polymer chains due to the re-usage of this material. All other mixtures show greater changes, but the measured values of the strength are less affected by recycling as a modulus of elasticity.

The last property that was evaluated was the relative strain, which exhibits a similar course of measured values as for the ultimate tensile strength. The elongation at the tensile test has been reduced, with lesser strength showing a lower elongation. Overall, the tensile mechanical properties deteriorated due to reuse of the used styrene acrylonitrile.

\section{ACKNOWLEDGMENTS}

This work was supported by the European Regional Development Fund under the project CEBIA-Tech Instrumentation No. CZ.1.05/2.1.00/19.0376 and by the Ministry of Education, Youth and Sports of the Czech Republic within the National Sustainability Program project no. LO1303 (MSMT-7778/2014). Moreover, it was supported by the Internal Grant Agency of TBU in Zlin: no. IGA/FT/2019/002.

\section{REFERENCES}

[Brandrup 1996] Brandrup, J. (ed.): Recycling and recovery of plastics, Munich, Hanser Verlag, 1996.

[Goodship 2007] Goodship, V., Introduction to plastics recycling. 2nd ed. Shawbury, U.K.: Smithers Rapra, 2007, 174 p. ISBN 978-1-84735-078-7.

[La Mantia 1993] La Mantia. F. P., Recycling of plastic materials. Toronto: ChemTec Pub., 1993, vi, 189 p. ISBN 18-951-9803-8.

[Manas 2018] Manas, D., et al. The Effect of Irradiation on Mechanical and Thermal Properties of Selected Types of Polymers, Polymers, 10 (2018), 158.
[Navratil 2015] Navratil J., et al. Recycling of irradiated high-density polyethylene, Radiation Physics and Chemistry, January 2015, Vol. 106, pp 68-72. ISSN 0969-806X

[Navratil 2014] Navratil J., et al. Influence of recycled irradiated HDPE on mechanical behavior of LDPE/Hdpex blends, 2014, Vol. 1025-1026, pp 265-269. ISSN 1022-6680

[Ovsik 2016] Ovsik, M., et al. he behaviour of cross-linking filled PBT measured by nano-hardness, MM Science Journal, 2016 (2016), 1110-1113-510.

[Ragan 2012] Ragan, E., et al. Dynamic of Taking out Molding Parts at Injection Molding. Metalurgija. Vol. 51. No. 4 (2012). pp. 567-570. ISSN 0543-5846.

[Scelsi 2011] Scelsi, L., et al. A Review on Composite Materials Based on Recycled Thermoplastics and Glass Fibres. Plastics, Rubber and Composites. (2011), vol. 40, ISSN: 1465-8011.

[Senkerik 2014] Senkerik, V., et al. Comparison of mechanical properties of different particle sizes of recycled polycarbonate at higher temperature (2014) International Journal of Mechanics, 8 (1), pp. 268-275.

[Senkerik 2016] Senkerik, V. et al. Effect of recycled particle size to micro-hardness properties of styrene acrylonitrile (2016) Defect and Diffusion Forum, 368, pp. 154-157.

[Skrobak 2014] Skrobak, A., Mechanical properties of rubber samples (2014) Key Engineering Materials, 606, pp. 249-252.

[Stanek 2011] Stanek, M., et al. Optimization of Injection Molding Process, International Journal of Mathematics and Computers in Simulation, Volume 5, Issue 5, 2011, p. $413-421$

\section{CONTACTS}

Ing. Vojtech Senkerik, Ph.D.

Tomas Bata University in Zlin

nam. T. G. Masaryka 5555, 76001 Zlin, Czech Republic

P+42057603 5100, vsenkerik@utb.cz, www.utb.cz

Ing. Martin Ovsik, Ph.D.

Tomas Bata University in Zlin

nam. T. G. Masaryka 5555, 76001 Zlin, Czech Republic

ovsik@utb.cz,www.utb.cz

Ing. Martin Reznicek, Ph.D.

Tomas Bata University in Zlin

nam. T. G. Masaryka 5555, 76001 Zlin, Czech Republic

mreznicek@utb.cz,www.utb.cz

Ing. Vaclav Janostik

Tomas Bata University in Zlin

nam. T. G. Masaryka 5555, 76001 Zlin, Czech Republic

vjanostik@utb.cz,www.utb.cz 